\title{
As Representações Sociais sobre a Maternidade para Mães em Privação de
}

\author{
Liberdade \\ Adriele Vieira de Lima Pinto* \\ Universidade Federal da Paraíba - UFPB, João Pessoa, PB, Brasil \\ ORCID: https://orcid.org/0000-0003-4126-1795 \\ Maria da Penha de Lima Coutinho** \\ Universidade Federal da Paraíba - UFPB, João Pessoa, PB, Brasil \\ ORCID: https://orcid.org/0000-0003-3961-2402 \\ Jaqueline Gomes Cavalcanti*** \\ Instituto Federal de Educação de Pernambuco - IESP, João Pessoa, PB, Brasil \\ ORCID: https://orcid.org/0000-0002-3068-404X \\ Karla Costa Silva**** \\ Instituto de Educação Superior da Paraíba - IFPE, Igarassu, PE, Brasil \\ ORCID: https://orcid.org/0000-0002-8454-3787
}

\section{RESUMO}

Diante do aumento do encarceramento feminino, ganharam visibilidade questões específicas deste público, dentre elas as relacionadas à maternidade. Este estudo objetivou conhecer a vivência da maternidade para mães privadas de liberdade, a partir do aporte teórico das Representações Sociais. Participaram 15 mães, com idade entre 21 e 44 anos $(M=30,47$; $D P=6,25)$ do Centro de Ressocialização Feminino de João Pessoa, Paraíba. Foram submetidas a entrevistas em profundidade e ao questionário sóciodemográfico. A produção textual foi processada com o auxílio do software ALCESTE e analisadas pela Classificação Hierárquica Descendente, os dados sóciodemográficos por meio do SPSS (versão 21). Dos resultados, emergiram quatro classes temáticas, ancoradas: na vivência e rotina diária na prisão; no conhecimento sobre processos, sentenças e morosidade da justiça; nas vulnerabilidades para o uso de substâncias psicoativas e suas consequências nas relações familiares; e na vivência da maternidade. Ser mãe, neste contexto, foi objetivado como sinônimo de sofrimento, incerteza e culpa pela ausência nos cuidados maternos e pela separação dos filhos e familiares. Destacase que a maternidade adquire diferentes facetas que ora se aproximam e ora se distanciam do ideal de maternidade socialmente disseminado. Assim, faz-se necessário promover ações sociais que busquem fortalecer os laços psicossociais entre as mães presas, suas famílias, filhos e sociedade.

Palavras-chave: maternidade, mães, privação de liberdade, representações sociais. 


\title{
Social Representations of Motherhood for Mothers Deprived of Liberty
}

\begin{abstract}
Faced with the increase in female incarceration, specific issues of this public gained more visibility, including those related to maternity. This study aimed to know the motherhood experience among mothers deprived of liberty from the perspective of theoretical contribution of Social Representations. Fifteen mothers, between 21 and 44 years old $(\mathrm{M}=30.47$; SD = 6.25) from the Centro de Ressocialização Feminino of João Pessoa, Paraíba participated. They were submitted to in-depth interviews and the socio-demographic questionnaire. The textual production was processed with the aid of ALCESTE software and analyzed by the Descending Hierarchical Classification, the socio-demographic data through the SPSS (version 21). From the results, four thematic classes emerged, anchored: in the experience and daily routine in prison; In the knowledgeof court proceedings, judgments and delays; in vulnerabilities to psychoactive substance use and their consequences on family relationships; and in the experience of motherhood. Being a mother, in this context, was objectified as a synonym of suffering, uncertainty and guilt for the absence of maternal care and separation of children and family. It is noteworthy that motherhood acquires different facets that are now approaching and away from the ideal of the socially disseminated motherhood. Thus, it is necessary to promote social actions that seek to strengthen psychosocial ties between imprisoned mothers, their families, children and society.
\end{abstract}

Keywords: maternity, mothers, deprivation of liberty, social representations.

\section{Las Representaciones Sociales sobre la Maternidad de las Madres en}

\section{Privación de Libertad}

\section{RESUMEN}

Frente al aumento del encarcelamiento femenino, ganaron visibilidad cuestiones específicas de este público, entre ellas las relacionadas a la maternidad. Este estudio objetivó conocer la vivencia de la maternidad de las madres privadas de libertad, a partir del aporte teórico de las Representaciones Sociales. Participaron 15 madres, de 21 a 44 años $(M=30,47$; DP=6,25) del Centro de Resocialización Femenino de João Pessoa, Paraíba. Se sometieron a entrevistas en profundidad y al cuestionario sociodemográfico. La producción textual fue procesada con el auxilio del software ALCESTE y analizada por la Clasificación Jerárquica Descendente, los datos sociodemográficos por medio del SPSS (versión 21). De los resultados, emergieron cuatro clases temáticas, ancladas: en la vivencia y la rutina diaria en la cárcel; en el conocimiento sobre los procesos, las sentencias y la morosidad de la justicia; en las vulnerabilidades para el uso de las sustancias psicoactivas y sus consecuencias en las relaciones familiares; y en la vivencia de la maternidad. Ser madre, en este contexto, fue objetivado como sinónimo de sufrimiento, inseguridad y culpa por la ausencia en los cuidados maternos y la separación de los hijos y familiares. Se destaca que la maternidad adquiere diferentes facetas que se acercan o se alejan del ideal de la maternidad socialmente diseminado. De esta forma, es necesario promover acciones sociales que busquen fortalecer los vínculos psicosociales entre las madres encarceladas, su familia, los hijos y la sociedad.

Palabras clave: maternidad, madres, privación de libertad, representaciones sociales. 
Nos últimos anos, com o aumento do encarceramento feminino no Brasil, as discussões sobre questões específicas dessa parcela da população foram ampliadas. Dentre elas, debates acerca dos direitos maternos, reprodutivos e sexuais das mulheres privadas de liberdade (Brasil, 2018; Brasil, 2015). Dessa forma, ainda que tardiamente, estas mulheres têm ganhado certa visibilidade nos diferentes setores da sociedade, bem como na representação em políticas e pesquisas (Brasil, 2015).

Atribui-se o período de invisibilidade desse público a questões históricas, nas quais a criminalidade feminina não era diferenciada da masculina (Novaes \& Maurari, 2010; Simões, 2013). Em contrapartida, França (2014) aponta que o envolvimento com o crime, assim como os vínculos com que as mulheres estabelecem suas relações dentro da prisão com seus familiares e filhos, apresentam-se, em geral, de maneira diferenciada, pois elas carregam consigo sistemas discriminatórios que alicerçam historicamente suas posições diante da sociedade (Alcântara, Sousa, \& Silva, 2018). Portanto, o aprisionamento feminino não poderia ser considerado do mesmo modo que o masculino, visto que as repercussões sobre si, sua família, filhos e sociedade são distintas.

Nessa direção, Braga (2015) pontua que a mulher privada de liberdade ocupa lugares opostos nos repertórios de papéis atribuídos às mulheres na sociedade. Estas são associadas, por um lado, às expectativas sociais e morais que lhes são depositadas (qualidades maternas, boa filha, esposa e mãe), pertencentes a uma visão estereotipada do ideal feminino. Por outro lado, as associam ao desvio criminoso, marcado pelo crime e delinquência. Assim, segundo Simões (2013), nas prisões femininas se exerce um regime disciplinar muito mais duro, pois as mulheres seriam duplamente punidas, pelo desvio criminoso e pelas transgressões das normas sociais que regulam o que se espera de sua condição feminina.

Diante deste cenário, em consonância com o notório crescimento da população prisional feminina, observa-se também um recente aumento na produção científica nacional que discute e analisa as especificidades desse público (Brasil, 2015; Cortina, 2015; Ferrari \& Fan, 2016; Germano, Monteiro, \& Liberato, 2018; Leal, Ayres, Esteves-Pereira, Sánchez, \& Larouzé, 2016). Essas investigações tornam-se relevantes, pois coadunam-se com a atuação das políticas públicas sociais e da saúde voltadas para esta população (Lermen, Gil, Cúnico, \& Jesus, 2015). Voltam-se especificamente à Política Nacional de Atenção às Mulheres em Situação de Privação de Liberdade e Egressas do Sistema Prisional - PNAMPE (Portaria n. 210, 2014), que tem como um dos objetivos principais: fomentar e desenvolver pesquisas relativas ao encarceramento feminino. De igual modo, o desenvolvimento desses estudos impulsiona a elaboração de conhecimentos, viabiliza recursos para a ampliação das demais 
políticas públicas, além de reunir diferentes áreas de conhecimento (ex. Psicologia, Saúde, Direito, Segurança, Educação), as quais contribuem para um olhar multifacetado e qualificado sobre as questões em pauta.

Nesse sentido, buscando contribuir com a produção científica nacional e alinhado aos objetivos da PNAMPE, o estudo em tela buscou desenvolver análises e reflexões acerca da vivência da maternidade no contexto prisional. Esta temática foi selecionada por ser um fenômeno social complexo e reunir uma série de consequências que reverberam nos diferentes cenários da vida destas mães (vínculos familiares, relações entre mãe e filho, relações de poder nas prisões, papéis de gênero, garantias de direitos) constituindo-se, portanto, como campo fértil para promover debates e produzir informações pertinentes que venham a diminuir os impactos que o encarceramento acarreta nesse contexto.

Associados a esses diferentes cenários de vida, as mães presas, no Brasil, são em sua maioria negras, jovens, solteiras, com baixa escolaridade e têm a associação ao tráfico de drogas como principal via de acesso à criminalidade e à prisão (Brasil, 2018; Leal et al., 2016). Ademais, essas mulheres carregam consigo trajetórias de vida historicamente, marcadas pela exclusão, desigualdade, racismo, patriarcalismo, estigmas e opressão (Alcântara, Sousa, \& Silva, 2018). É nesse cenário de intensas vulnerabilidades que muitas mulheres experienciam a maternidade, cuja função ganha novas nuances diante do contexto prisional.

Alguns dos fatores associados a esta nova realidade estão relacionados à negligência e desatenção aos direitos humanos por parte do sistema judiciário, o qual provoca danos às mulheres privadas de liberdade, como perda de suas filhas e filhos e o impedimento da manutenção dos vínculos familiares (Brasil, 2015). Por sua vez, as instituições que asseguram o exercício da maternidade acabam tirando o poder de decisão das mulheres presas, quanto a escolha de se e como querem cuidar dos seus filhos. Isto produz uma validação dos saberes médicos, administrativos e jurídicos no que diz respeito a padrões normativos de conduta impostos às mulheres dentro das prisões, gerando assim uma naturalização do papel materno feminino e a não autonomia do exercício da maternidade (Brasil, 2015). Segundo Leal Ayres, Esteves-Pereira, Sánchez e Larouzé (2016), esta realidade viola o que preconiza a Constituição Federal, uma vez que as mulheres presas deveriam se beneficiar do mesmo tratamento que a população livre recebe.

Em consonância, o exercício materno no contexto prisional, de maneira geral, está mediado por mecanismos de controle institucional que, segundo Cúnico, Brasil e Barcinski (2015), são frequentemente justificados e legitimados, em especial quando associados à 
possibilidade de ressocialização. A instituição prisional, no intuito de tentar ressocializar estas mulheres, acaba evidenciando a domesticidade feminina, sobretudo a expectativa de que elas desejam reassumir suas funções maternas. Dessa forma, as mães em situação de prisão são culpabilizadas por não desempenharem sua função materna e por, aparentemente, não terem pensado nos filhos no momento em que cometeram os crimes.

Lima, Pereira Neto, Amarante, Dias, e Ferreira Filho (2013) indicam que o significado da maternidade na prisão abarca uma série de experiências vivenciadas por múltiplos sentimentos (tristeza, solidão, perda, dor, saudade), intensificados pelo processo de encarceramento. Em consonância, Lima (2013) aponta a recorrência dos sentimentos de tristeza, dor e desesperança por parte das encarceradas que são mães, visto que essas relatam o abandono dos familiares, amigos e sobretudo a separação dos filhos.

Nesse sentido, Leal et al. (2016) avaliam que os impactos do afastamento da família, sobretudo dos filhos, em relação à mãe encarcerada são nocivos não apenas para as crianças, mas para a sociedade como um todo. Visto que as consequências produzidas para os filhos dessas mulheres, não somente os que estão na prisão, como também aqueles fora dela, atenuam ciclos de exclusão e vulnerabilidade social. Nesse sentido, o Instituto de Pesquisa Econômica Aplicada (IPEA) indica que os esforços e atenção das gestoras e idealizadoras de políticas prisionais devem estar voltados também para esta população invisível, de filhos e filhas, visto que, os direitos dessas crianças e adolescentes, quanto à alimentação, cuidados, assistência material e afetiva, devem ser resguardados (Brasil, 2015).

Diante dessas premissas, ao se estudar a temática da maternidade no contexto prisional, deve-se considerar que as mulheres inseridas neste ambiente trazem consigo uma história de vida, agindo em função de suas crenças, percepções, sentimentos, valores e comportamentos. Estes possuem sentidos e significados que precisam ser identificados, uma vez que são construídos e compartilhados socialmente (Coutinho \& Do Bú, 2017; Chaves \& Silva, 2013). Portanto, ainda que as mães estejam em privação de liberdade, faz-se necessário buscar olhar o fenômeno para além dos muros que as isolam.

Dessa forma, para nortear o estudo em tela, utilizou-se como enfoque teórico um olhar psicossocial, proporcionado pela Psicologia Social, e subsidiado pela teoria das Representações Sociais (RS). Assim, a maternidade foi concebida como uma construção social, processo complexo, multifacetado, que está em constante transformação. Analisou-se a temática a partir da apreensão do processo de produção e elaboração das construções particulares das realidades sociais das mulheres privadas de liberdade, bem como pelo 
processo de organização do seu sistema de conhecimento do senso comum, de ideias e valores (Franco, 2004; Moscovici, 2012).

Diante dessas premissas, o presente estudo foi delineado no intuito de responder a seguinte pergunta: Como mães em privação de liberdade vivenciam a maternidade? Para tanto, objetivou-se apreender as representações sociais acerca da maternidade, elaboradas por esta população. Especificamente, buscou-se compreender a vivência do encarceramento; investigar as implicações que este provoca ao exercício da maternidade e na relação entre mãe e filho.

\section{Método}

Trata-se de uma pesquisa de campo, transversal, do tipo exploratória-descritiva e analítica. A pesquisa foi subsidiada por uma abordagem psicossociológica, ancorada na Teoria das Representações Sociais de Moscovici.

\section{Participantes}

Contou-se com a participação de 15 mães em privação de liberdade, com idade entre 21 e 44 anos $(M=30,47 ; D P=6,25)$, que se autodeclararam pardas. A maioria era solteira $(n=10)$, estudou até o ensino fundamental incompleto $(n=9)$, tinha entre 1 a 6 filhos $(M=2,87$; $D P=1,40)$. A classe socioeconômica foi identificada como: baixa $(n=4)$, média-baixa $(n=3)$ e média $(n=8)$. Para este item utilizou-se a seguinte pergunta 'Em comparação com as pessoas da sua cidade, você diria que a sua família é de qual classe socioeconômica?', em seguida eram apresentadas as alternativas supracitadas, complementadas por mais duas (média-alta e alta) que não foram identificadas por nenhuma das mulheres.

Quanto ao tempo na prisão, a maioria estava a menos de um ano em privação de liberdade $(n=6)$, era reincidente $(n=9)$ e usava drogas fora da prisão $(n=10)$. Cinco delas declararam usar medicações de uso continuado para as seguintes enfermidades: anemia $(n=2)$, depressão $(n=1)$, vírus HIV ( $n=1)$ e hipertensão $(n=1)$. Doze possuíam sentença condenatória, e estavam cumprindo pena para os seguintes crimes: tráfico de drogas $(n=4)$, furto $(n=1)$, roubo $(n=4)$ e homicídio $(n=4)$. Adotou-se como critérios de inclusão: estar em regime fechado, ser mãe, e o critério de saturação teórica para suspender a inclusão de novas participantes, a partir da redundância e repetição dos dados que foram obtidos. 
A pesquisa foi desenvolvida em um Centro de Reeducação para Mulheres, localizado no município de João Pessoa/PB. Na ocasião, encontrava-se reclusa uma gestante, quatro mulheres que tiveram seus filhos quando já estavam presas e as demais foram separadas dos filhos no momento da prisão. Aquelas que tiveram os filhos no centro de reeducação, relataram que no período da gestação, foram transferidas para uma cela específica, provida de camas, berços, mosquiteiros, enxoval completo, fraldas, cadeira para amamentar, ventilador, televisão, som. As mães permaneciam no local pelo período de seis meses, tempo mínimo estabelecido para a amamentação, em seguida seus filhos eram entregues aos familiares.

Das participantes da pesquisa, oito relataram receber visitas dos filhos que, em sua maioria, iam acompanhados pela avó materna. As visitas ocorriam aos domingos das $8 \mathrm{~h}$ às 15h. Devido a condição socioeconômica, e por muitos familiares morarem em cidades mais distantes do centro de reeducação, a frequência das visitas variaram, em intervalos de quinze dias a um mês.

\section{Instrumentos}

Utilizou-se um questionário sociodemográfico com a finalidade de obter informações sobre o perfil das participantes, com itens como: idade, sexo, escolaridade, estado civil, quantidade de filhos, renda, raça/etnia, sentença condenatória, artigos do código penal que foram enquadrados os crimes, reincidência e uso de drogas. Fez-se uso também da entrevista em profundidade, utilizada com a finalidade de obter o maior número possível de informações e detalhamento sobre a temática em questão. A mesma é utilizada geralmente na compreensão de especificidades culturais que abrangem vários âmbitos (experiências do dia a dia, questões psicossociais, elementos históricos, dentre outros) elaborados com base na linguagem do senso comum, sendo esses aspectos necessários para a apreensão das representações sociais de determinados grupos (Minayo, 2012; Nogueira-Martins \& Bógus, 2004).

\section{Coleta de Dados}

A pesquisa foi aprovada pelo Comitê de Ética em Pesquisa da Universidade Federal da Paraíba - CEP/CCS, sob o protocolo de $\mathrm{n}^{\mathrm{o}}$ 2.513.580. Foram acatados todos os preceitos éticos preconizados pela Resolução 466/2012, do Comitê de Ética em Pesquisa com Seres Humanos. A pesquisa foi realizada nas dependências do centro de reeducação feminino, após aprovação da proposta de estudo pela Gerência Executiva de Ressocialização do Estado da 
Paraíba e pela gestora da instituição pesquisada. Nos dias da aplicação, a pesquisadora dirigia-se à chefe de disciplina da instituição e, após sua liberação, era conduzida aos dois pavilhões nos quais estavam as mulheres presas. No local, a pesquisadora era recebida pelas agentes penitenciárias de plantão, que traziam as mães e organizavam o local para a pesquisa. Esta ocorria, individualmente, via de regra, na sala de estudos ou na área destinada para as visitas dos domingos. Além disso, somente foi aplicado o material da pesquisa, após a assinatura do Termo de Consentimento Livre e Esclarecido pelas participantes. Na ocasião, foi orientado sobre o sigilo referente à identidade das mulheres e da não obrigatoriedade de participação, apesar da autorização prévia da instituição. As entrevistas foram gravadas e, posteriormente, transcritas de forma literal. O tempo total de aplicação dos instrumentos foi, em média, de 35 min.

\section{Análise dos Dados}

Os dados do questionário sociodemográfico foram processados por meio do IBM SPSS (versão 21) e analisados por meio de estatística descritiva (frequência, porcentagem, média e desvio padrão). Por sua vez, as 15 entrevistas transcritas e codificadas foram processadas pelo software ALCESTE, desenvolvido por Reinert (1993), cujo método de estatística textual permite identificar a organização tópica do discurso, tornando-se possível a análise psicossocial da linguagem oral e escrita (Saraiva, Coutinho, \& Miranda, 2011). O programa computacional quantifica o texto para evidenciar estruturas com significados mais representativos e acessar informações fundamentais presente no texto. Ademais, sua concepção e processamento permitem a análise da linguagem das representações sociais que organizam e dão forma ao pensamento e ao conhecimento social (Saraiva et al., 2011).

Dessa forma, foram realizadas: a descrição da frequência simples e do percentual das palavras, seguida do cálculo do $\chi 2$ e; a Classificação Hierárquica Descendente (CHD). Esta consiste em destacar cada palavra de uma determinada classe representando sua relação com outras palavras com base na proximidade de conteúdo do total do corpus, em um gráfico com formato de dendrograma (Saraiva et al., 2011).

\section{Resultados}

Considerando como parâmetro o dendrograma das quatro classes (Figura 1) que emergiram a partir da CHD, é possível observar o modo como foram difundidas as 
representações sociais acerca da maternidade e conhecer suas especificidades no contexto penitenciário. O corpus foi constituído por 15 unidades de contexto iniciais (U.C.I), totalizando 22.382 ocorrências, sendo 2.519 palavras distintas, tendo 4 ocorrências, em média, por palavra. Após a redução do vocabulário às suas raízes, foram encontradas 441 palavras reduzidas e analisáveis e 443 unidades de contexto elementares (U.C.E). A CHD reteve $51 \%$ do total das U.C.E. do corpus, distribuídas em quatro classes.

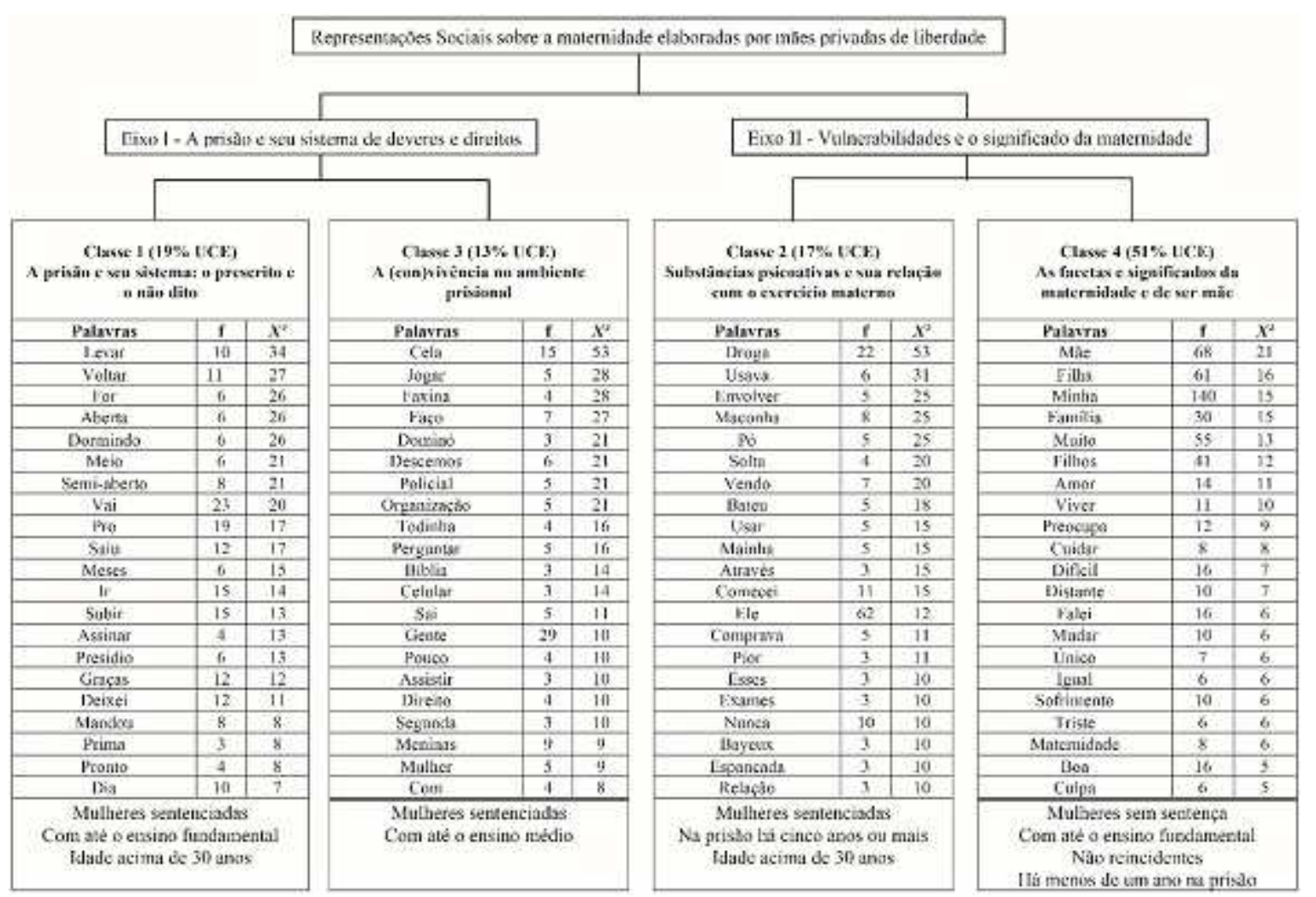

Figura 1. Dendrograma da Classificação Hierárquica Descendente.

De acordo com o dendrograma houve a primeira partição do corpus em dois subcorpora, ou eixos. Um deles resultando do agrupamento da Classe 1 e 3 , que compuseram o primeiro eixo, nomeado "A prisão e seu sistema de deveres e direitos", o qual abrangeu a dinâmica e os arranjos das relações estabelecidas no contexto penitenciário. Por sua vez, a segunda repartição, composta pelas classes 2 e 4, compôs o segundo eixo e contemplou a temática sobre as "Vulnerabilidades e o significado da maternidade", no qual são identificadas as trajetórias de vulnerabilidades associadas aos sentidos e significados atribuídos à maternidade. A seguir são apresentadas as classes e suas principais características, seguindo a ordem de partição do corpus textual representado no dendrograma na Figura 1. 
A Classe 1, nomeada "A prisão e seu sistema: o prescrito e o não dito", envolveu 43 U.C.E, com 51 palavras, correspondendo $19 \%$ do corpus; foi composta por palavras e radicais no intervalo e frequência entre $\chi 2=34$ (levamos, levando, levar, levava, leve) e $\chi 2=5$ (primeiro). As variáveis-atributos que mais contribuíram para esta classe foram: mulheres sentenciadas, com até o ensino fundamental e idade acima de 30 anos. A seguir são apresentadas algumas U.C.E. que justificam a denominação da Classe 1, esta trata-se de questões sobre o (des)conhecimento do processo condenatório, a morosidade da justiça e os relatos que denunciam violações de direito:

[...]Fico apelando no banho de sol aqui pra subir pra ver se eu sei de alguma coisa. Não sei de que jeito eu vou sair, só Deus sabe [...] eu tenho que morar aqui pra tirar a semiaberta porque eu vou voltar pro meu regime de novo. Na semiaberta se tranca todo dia de noite, na aberta a gente só se tranca no sábado e sai na segunda de manhã. A juíza deu o prazo e até agora não chegou [...]ter que passar uns dias na semiaberta, uns dois meses a três meses, ela disse, pra me poder ir pro direito da aberta. Mas, imagine você, passar esse tempo todo, aí o processo vai pro tribunal, passa um ano pra voltar, você já tem tirado tudo [...] foi um erro dele (advogado), ele não justificou, aí a juíza mandou um ofício pra mim, foi pro meu endereço antigo, eu não recebi. Aí saiu um mandato de prisão, faz cinco meses que eu tô aqui [...] é muito gasto, meu pai já gasta com gasolina e feira, e ainda trazendo mais duas, três crianças. Se eu for transferida, eu vejo eles, porque é bem pertinho lá de casa o presídio [...] eu subi (setor administrativo da prisão), aí me disseram: olhe é pra levar o menino pra casa, aí eu disse: 'oxente porque não avisaram, eu disse'. Eu disse: 'ow mulher, deixa eu ficar até amanhã com ele ou até o outro domingo'. Aí ela 'não, vai agora, você vai assinar e ele vai agora' [...] como minha filha vai se sentir no meio da sociedade porque tem muita gente que é discriminada aqui dentro.

Ainda no primeiro eixo, a Classe 3 , denominada "A (con)vivência no ambiente prisional”, obteve 29 U.C.E e 42 palavras, contabilizando 13\% do corpus, sendo a que menos contribuiu. Foi constituída por palavras e radicais no intervalo de $\chi 2=53$ (cela) e $\chi 2=4$ (dentro), identificados nos relatos das mulheres que já são sentenciadas, e que cursaram até o ensino médio. Essa classe abrange a rotina e a dinâmica das relações estabelecidas no ambiente carcerário: 
[...]Aqui eu faço faxina, fico assistindo televisão na cela, de vez em quando jogo dominó, me deito vou dormir, leio uma palavra na bíblia, fico conversando com as meninas da cela. Assim é o dia-a-dia da gente. Aí de manhã tem o banho de sol, tem a dança, a aula de dança também que a gente participa do grupo da juíza. É bom que ela ajuda com o processo da gente [...] porque as faxinas das celas sou eu que faço, são tudo paga pra quem faz, recebe o pagamento uma derb (marca de cigarro), um lanche, alguma coisa, entendeu? Aí a polícia vai e chama 'olha vá organizar a cela que tá feia' [...] aí tem que organizar, pintar, organizar, assim normal. Aí me acordo de nove horas da manhã, faço a faxina, depois a gente vai assistir televisão, jogar dominó, depois vai dormir [...] a gente fica parada o tempo todinho num cubículo bem pequenininho com vinte mulheres, aí quando sai pra fora pra dançar é bom demais. É uma hora de dança [...] comecei a estudar dentro da cela, a gente assiste televisão, conversa uma com a outra, escreve, às vezes tem alguma discussão, mas é coisa besta, as agentes chegam normal, pra mim é tranquilo, quando eu tô tranquila.

A Classe 2, que integra o segundo eixo do subcorpora, foi denominada como "Uso de substâncias psicoativas e sua relação com o exercício materno”, formada por 38 U.C.E, contendo 52 palavras, significando $17 \%$ do corpus; apresentou palavras e radicais no intervalo e frequência significativa entre $\chi 2=53$ (droga, drogar, drogas) e $\chi 2=4$ (tivesse), representada por mulheres sentenciadas, com idades acima de 30 anos, que estão na prisão há cinco anos ou mais. Esta classe apresenta, principalmente, os contextos e trajetórias de vulnerabilidades, associados ao uso de substâncias psicoativas e suas consequências nocivas para a vida dos filhos:

[...]Dizia ‘mainha porque a senhora sai tanto de casa?’ Aí eu dizia que trabalhava, só não dizia o que era. Eu nunca dizia o que fazia, tirei a mais nova do peito logo cedo porque não tinha como eu sair pra o ponto de tráfico [...] eu comprava uma lata de leite, que ela nasceu com poucos quilos através das drogas [...] quando eu tava fora, grávida, eu usei droga. Eu gostava de ficar esperta que era o pó, cocaína, mas não era nem direto, mas a minha pior droga mesmo era a bebida. Quando eu tava grávida dessa agora há pouco, eu usava loló, usei muito no começo da gravidez, eu sabendo que estava ofendendo a minha filha [...] eu estava foragida tinha medo de ser presa. Então, nos primeiros quatro meses lá fora não fiz exame. Praticamente eu não tive acompanhamento na rua [...] quando eu sair, a primeira coisa que eu vou fazer é 
procurar meus filhos. Depois que eu fiquei sabendo que um deles tá vendendo droga, tá usando droga $[\ldots]$ hoje ela toma remédio controlado, minha filha. Aí fez exame na cabeça dela e deu um distúrbio através das drogas que eu usava, cheguei a usar o crack até os nove meses. Soube agora que consumiu maconha. Dói muito porque eu não quero isso pra minha filha, ela tem treze anos. Às vezes, diz que preferia eu morta, muita coisa.

$\mathrm{Na}$ sequência, a Classe 4, foi categorizada como "As facetas e significados da maternidade e de ser mãe”, conteve 117 U.C.E. e 66 palavras, expressando 51\% das U.C.E. Composta por palavras e radicais no intervalo de $\chi 2=21$ (mãe) e $\chi 2=4$ (domiciliar). Assim, apesar de sua presença em quase todas as classes, a temática discutida neste estudo encontrase reunida com maior representatividade na Classe 4. As variáveis-atributos que mais contribuíram com esta classe foram: mulheres que aguardam o julgamento da sentença, estão na prisão pela primeira vez, a menos de um ano, possuem até ensino fundamental e idade entre 21 e 30 anos. A seguir, estão reunidas algumas UCE representativas da Classe 4, que trata das diferentes formas de vivenciar a maternidade e suas repercussões na relação mãefilhos, geradas pela condição de privação de liberdade:

[...]É triste porque eu fico pensando nos meus filhos. Podia tá perto deles e por erro meu mesmo (devido ao crime cometido), hoje eu tô distante. Aí eu me culpo e eu não tô me sentindo uma mãe que eu queria ser, prestativa com meus filhos [...] eu queria ter saído com ele né, todo sonho de mãe, aí eu vim pro corredor (pavilhão das sentenciadas) a pior tristeza que tem [...] eu tenho seis filhos pequenos, aqui fica difícil, porque machuca muito a distância. Meus filhos nunca se separou de mim da vez que se separou que tá demorando é essa e me machuca muito [...] distante dos filhos isso machuca demais, é muito ruim e faz cinco meses que eu não vejo eles, que não tenho visita também, não quis, eles sofriam muito [...] tá sendo difícil também, porque meu filho mais novo chega aqui e ele não me chama de mãe, ele chama minha mãe de mãe. Aí é difícil dói demais [...] eu só converso com meu advogado, ele praticamente virou minha família, só que minha mãe manda as coisas por ele, eu queria falar com ela pra que ela viesse, mas ela não vem. Já vai fazer quatro meses e eu não tenho nada de visita [...] meu filho não tava tendo gosto de se arrumar, de brincar com os amiguinhos só no canto da parede calado, triste. 


\section{Discussão}

A partir das interlocuções, é possível evidenciar que as representações sociais (RS), na classe 1, foram ancoradas nos mecanismos legais e sociais utilizados pelo Estado para legitimar o controle sobre as mães que estão presas. Essas estratégias encobrem muitas das possibilidades de exercício da maternidade e revelam um sistema de justiça omisso, uma vez que, esse dispositivo legal permite que uma mesma medida ao garantir direitos produza violações, condicionando e alimentando ciclos de exclusão. Esses elementos podem ser identificados nas falas das participantes, quando expressam a dificuldade de obterem informações sobre o andamento do processo penal e o descumprimento e imprecisão dos prazos para mudanças de regime.

Em consonância, a precarização do acesso à justiça por parte das mulheres presas, também é retratada na pesquisa de âmbito nacional, realizada pelo IPEA, em estudo que revela alguns elementos identificados como entraves ao exercício dos direitos no ambiente prisional feminino. Dentre eles estão a falta de normas padronizadas para condutas institucionais, a restrição de quadros de profissionais das Defensorias Públicas Estaduais para atender a demanda desta população, e a falta de meios institucionais nas prisões que viabilizem a comunicação entre defensora e defendida (Brasil, 2015).

Outros três elementos, expressos nas interlocuções das entrevistadas, estão relacionados especificamente ao exercício da maternidade. O primeiro retrata a falta de comunicação e preparação psicossocial da instituição para o processo de separação mãe-bebê. O segundo manifesta a necessidade de transferência para que o cumprimento da sentença ocorra em localização próxima à residência dos familiares e filhos. E o terceiro retrata o estigma social que as mulheres carregam por estarem na prisão e sua repercussão no tratamento que seus filhos podem receber a partir disso. Nos três casos, observa-se o descumprimento das políticas e leis voltadas para a população feminina em privação de liberdade.

Evidencia-se que os relatos das participantes denunciam a inobservância da instituição sobre o que é preconizado pela PNAMPE, que possuem dentre as metas: a) garantir assistência jurídica e acesso à informação sobre direitos e procedimentos de execução penal; b) assegurar o atendimento psicossocial para a efetivação do direito à convivência familiar; c) desenvolver ações de preparação para a saída da criança do estabelecimento prisional e sensibilização dos responsáveis ou órgãos por seu acompanhamento social e familiar. Esta omissão no cumprimento e execução dos direitos das mulheres privadas de liberdade é um 
problema de âmbito nacional, que traz repercussões negativas e perpetua ciclos de violações de direitos, exclusão e discriminação, extensivos a seus familiares e filhos (Brasil, 2015).

Em seguida, na Classe 3, a difusão das RS foi ancorada por aspectos referentes à esfera relacional e à manutenção do cotidiano prisional. Trata-se substancialmente, de mecanismos disciplinares, diluídos nos discursos descritivos sobre a rotina na prisão. As objetivações indicadas na CHD (cela, jogar, faxina, faço, dominó, descemos, policial, organização) confirmam esse argumento. Assim como nas U.C.E. representativas da classe, o cotidiano das mulheres entrevistadas é marcado, em geral, por atividades que não asseguram a reintegração social e o abono da pena, mas endossam a manutenção do controle, a hierarquização das relações estabelecidas nesse contexto, e a reprodução de tarefas tradicionalmente destinadas as mulheres no lar.

Esta evidência confirma as análises de Pádua e Barros (2018) sobre a precarização das condições de trabalho nas prisões, uma vez que a maioria das atividades desenvolvidas são desprovidas de garantias legais como aquelas atribuídas aos trabalhadores livres, não levam em consideração habilidades profissionais adquiridas anteriormente a prisão e, muitas vezes, não possuem vagas suficientes.

Acrescidos a isso, os resultados desta classe confirmam os estudos de Braga (2015), o qual menciona que os mecanismos de controle sobre as mulheres e mães em privação de liberdade são constituídos por práticas formais e informais, resultantes de arranjos de poder, forjados em políticas penitenciárias que, historicamente, excluem as mulheres e suas especificidades. Essas práticas podem ser identificadas nos relatos que descrevem a rotina de atividades das mulheres, a qual é preenchida, em sua maioria, por tarefas domésticas, de organização e limpeza do ambiente prisional, em troca de pequenos "agrados" (cigarros, um lanche). Por trás dessa dinâmica "formal", capaz de garantir o bom comportamento e funcionamento prisional, encontram-se procedimentos, deveres e direitos que se distanciam daqueles previstos nas recentes políticas pensadas para elas. Esses arranjos são mais explícitos e justificados quando associados à maternidade e à possibilidade de ressocialização (Cúnico et al., 2015).

Ademais, o relato das mulheres sobre a superlotação nas celas também é uma realidade na maioria das unidades prisionais do Brasil. Esses dados corroboram as informações sobre a taxa de ocupações registrada em junho de 2016, que chegou a 156,7\%, indicando que num espaço destinado a 10 mulheres, encontravam-se, em média, 16 custodiadas (Brasil, 2018). 
Por sua vez, na Classe 2, as RS acerca da maternidade ganham novos arranjos, ancoradas em condutas de vulnerabilidades devido ao uso e comercialização de drogas, e em implicações psicossociais no vínculo entre mãe e filhos. As objetivações utilizadas nos discursos das mulheres nesta classe (droga, usava, envolver, maconha, pó, solta, vendo), corroboram evidências que demonstram a forte relação entre este público e a associação com o tráfico e uso de drogas (Braga, 2015; Diuana, Corrêa, \& Ventur, 2017).

Nessa direção, de acordo com o INFOPEN, 62\% das incidências penais que envolvem mulheres condenadas, ou que aguardavam julgamento em 2016, estavam relacionadas ao tráfico de drogas. De outa maneira, pode-se dizer que $3 \mathrm{em}$ cada 5 mulheres que estão no sistema prisional respondem por crimes ligados ao tráfico (Brasil, 2018). Associados a isso, são destacadas nas falas das entrevistadas os diversos riscos e consequências psicossociais que o uso de entorpecentes e do álcool acarretaram, principalmente, na vida dos filhos.

As implicações psicossociais identificadas através das narrativas das mães em privação de liberdade foram: a) o desmame precoce para poder voltar a traficar; b) a necessidade de suplementação alimentar e o uso de medicação controlada para os filhos, devido ao consumo de drogas durante a gestação; c) a falta de acompanhamento pré-natal extramuros; d) e a preocupação do envolvimento dos filhos no consumo e associação ao tráfico de drogas. Muito embora essas questões estejam também relacionadas à saúde pública, os danos psicossociais causados pelo uso das drogas, reverberam de forma ampla, na qualidade das relações socioafetivas entre mãe e filho, bem como reforçam a imagem de transgressoras, tanto da lei quanto do comportamento prescritivo ao gênero feminino (França, 2014; Simões, 2013).

Por fim, a classe 4 retratou as RS acerca da maternidade ancoradas na esfera de ordem emocional, objetivadas pelos termos: machucar, culpa, triste e sofrimento; frequentemente expressados nas U.C.E. No dendrograma, a palavra mãe representou a crença central acerca da maternidade, seguida das objetivações (filhos, família, amor, cuidar, boa). Ademais, a experiência materna, no cárcere foi associada às seguintes palavras: difícil, distante, sofrimento, triste, culpa.

Em conformidade com a pesquisa de Diuana et al. (2017), uma parte desses elementos representou formas de compreender a função materna, que a princípio, parece não ter muita diferenciação entre "ser mãe" dentro ou fora da prisão. Considerando que características como se preocupar, cuidar e sofrer são representações que sustentam o imaginário social acerca do que se espera de uma boa mãe. Nesse sentido, a apropriação dos significados das RS sobre a maternidade, compartilhados pelas mães privadas de liberdade, associa-se também ao status 
especial sobre o papel moral da boa mãe, valorizado socialmente e reforçado pelas práticas institucionais nas prisões.

Observa-se, no entanto, que alguns desses elementos ganham contornos específicos frente a condição do encarceramento, estes podem ser evidenciados a partir dos relatos que apontam para a perda de laços afetivos e abandono familiar, sendo este um dos principais elementos que caracterizam a diferenciação entre a vivência da maternidade dentro e fora da prisão. Associados a isso, segundo os estudos de Lima (2013), a atmosfera de ausências e violações de direito que, em geral, retratam as instituições prisionais estão para além do isolamento penal e configuram-se como ameaças à saúde mental destas pessoas.

O reduzido quantitativo de presídios femininos distribuídos pelo território nacional, constitui outro elemento potencializador para o distanciamento familiar e perda dos laços psicossociais dessas mulheres. Esta realidade ocasiona a concentração das apenadas em penitenciárias distantes do seu lugar de origem, consequentemente longe dos seus filhos e familiares, reforçando assim o abandono e a perda dos vínculos (Simões, 2013). Assim como evidenciado nos relatos das participantes, esta distância física também gera renúncia por parte das mulheres presas às visitas semanais dos seus familiares e filhos, no intuito de poupá-los dos gastos com deslocamento e do constrangimento das revistas para entrada no espaço da visitação (Jesus, Oliveira, Oliveira, Brandão, \& Costa, 2015).

Foi emergida também na Classe 4, a palavra domiciliar, esta qualificada como pena não privativa de liberdade, prevista pela Lei de Execução Penal, localizada na regra $n^{\circ} 64$ (Brasil, 2015). O surgimento da palavra nesta classe pode ter relação direta com a difusão da concessão realizada pelo Supremo Tribunal Federal (STF), referente ao habeas corpus coletivo de $\mathrm{n}^{\mathrm{o}} 143.641$, de 20 de fevereiro de 2018. Este foi publicado, concomitantemente, no mesmo período em que ocorreram as entrevistas que compuseram a seguinte pesquisa. $\mathrm{Na}$ decisão, o STF substitui a prisão preventiva pela domiciliar destinada às mulheres presas gestantes, ou mães de crianças de até 12 anos ou de pessoas com deficiência, em todo o território brasileiro, sem danos à aplicação das medidas alternativas previstas pelo Código de Processo Penal.

Ressalta-se ainda que as variáveis-atributos da classe 4 contribuíram de forma hegemônica para a elaboração, apropriação e difusão das RS sobre a vivência da maternidade no contexto prisional. Em razão das participantes estarem em privação provisória de liberdade, terem entre 21 e 30 anos, estarem presas pela primeira vez e há menos de um ano, configurando evidências de que a experiência materna em privação de liberdade é recente e, portanto, são questões que parecem vir à tona de forma mais latente. 


\section{Considerações Finais}

Dessa forma, o estudo em tela buscou, em sua totalidade, ampliar a análise e discussão dos elementos representacionais acerca da maternidade no contexto prisional. Para tanto, analisou-se os relatos de mães privadas de liberdade, organizados por meio de quatro classes temáticas geradas pela Classificação Hierárquica Descendente. Como ponto inicial de análise, observou-se que os relatos das mulheres evidenciaram as diferentes formas de controle e omissão por parte do Estado ao aplicar medidas que não asseguram a reinserção social. Como consequência, as falas denunciam, o acesso deficitário às informações acerca dos seus direitos, perpassadas por uma atmosfera de estigmas refletidas nas descrições das práticas disciplinares, formais e informais, que reforçam a desigualdade de gênero.

Nesse direcionamento, observou-se que na Classe 3, foram agrupados relatos sobre a vivência do encarceramento, sendo alcançado um dos objetivos do estudo. Muito embora não tenham se evidenciado relatos diretos que especificassem sua relação com a maternidade, tornou-se relevante estudar os elementos representacionais dessa classe, pois a mesma viabilizou o acesso à compreensão da rotina no ambiente prisional, bem como as condições enfrentadas pelas mães privadas de liberdade no decurso do cotidiano.

Outro ponto analisado reuniu elementos mais fortemente relacionados ao contexto da maternidade, sendo marcado inicialmente, por relatos de experiências de vulnerabilidades que antecederam a prisão. As falas das mulheres revelaram um passado de negligências para consigo e seus filhos, principalmente devido ao uso e comercialização de drogas. Esses discursos apontaram também para a fragilização nas relações socioafetivas estabelecidas antes mesmo da prisão.

Ao ingressarem no ambiente carcerário, muitas mães se depararam com uma realidade difícil, quase sempre associada a ausências de visitas, por dificuldades para manterem os vínculos com os filhos, e pela própria ambivalência dos sentimentos atribuídos à vivência da maternidade. Este paradoxo de sentimentos (amor, cuidar, boa, triste, sofrimento, culpa), presentes e atuantes, na experiência materna, traz à tona outros sentidos e significados imbricados sobre o papel valorativo que a maternidade exerce no cárcere, uma vez que socialmente ter essas características dá a mulher o status de boa mãe.

Nesse sentido, a representação positiva quanto ao papel de mãe é, portanto, reforçada, no cárcere, por práticas institucionais que entendem que as mulheres que buscam manter o contato com os filhos e cuidam bem deles têm mais chances de reabilitação. Por outro lado, a aquisição desse papel dá a mãe presa, a possibilidade de olhar a si mesma para além do ato 
criminoso, colocando-se como membros valiosos da sociedade por desempenharem a função de mães (Cúnico et al, 2015).

Diante desses apontamentos, faz-se necessário promover espaços colaborativos para que sejam fortalecidos e desenvolvidos laços e vínculos sociais e afetivos, entre as apenadas, seus filhos e família, tendo em vista o papel protetivo que estes desempenham no processo de institucionalização, na reinserção social e na diminuição das reincidências. Ações devem ser formuladas e executadas tendo foco no desenvolvimento das potencialidades (profissionais e pessoais) dessas mulheres, no resgate da dignidade, na orientação para possibilidades de novas trajetórias de vida, no acesso a informações acerca dos seus direitos e dos seus filhos e, na promoção da saúde, principalmente mental.

O foco dessas ações, portanto, não estaria no julgamento moral dos crimes, mas na garantia da efetiva reinserção social dessas mulheres. Não obstante, devem ser colocadas em pauta problematizações acerca da lógica punitivista adotada pelo Estado e seu sistema prisional, que naturaliza as violações de diretos e permite a invisibilidade das especificidades que as mulheres privadas de liberdade trazem consigo.

Como limitações do estudo, aponta-se para prováveis omissões nos relatos das mulheres sobre as condições de vida e vivência da maternidade dentro da prisão, uma vez que a pesquisa foi aplicada no próprio ambiente de privação de liberdade. Outro ponto diz respeito a mediação ocorrida pelas agentes penitenciárias na convocação e condução das participantes para a pesquisa, não sendo permitido à pesquisadora esse contato inicial direto com as apenadas.

\section{Referências}

Alcântara, R. L. S., Sousa, C. P. C., \& Silva, T. S. M. (2018). Infopen Mulheres de 2014 e 2018: Desafios para a Pesquisa em Psicologia. Psicologia: Ciência e Profissão, 38(spe2), 88-101. doi:10.1590/1982-3703000212154

Braga, A. G. M. (2015). Entre a soberania da lei e o chão da prisão: A maternidade encarcerada. Revista Direito GV, 11(2), 523-546. doi:10.1590/1808-2432201523

Brasil (2014). Portaria $n^{o}$ 210, de 16 de janeiro de 2014. Institui a Política Nacional de Atenção às Mulheres em Situação de Privação de Liberdade e Egressas do Sistema Prisional, e dá outras providências. Brasília, DF: Diário Oficial da União. Recuperado de 
http://www.lex.com.br/legis_25232895_PORTARIA_INTERMINISTERIAL_N_210_ DE_16_DE_JANEIRO_DE_2014.aspx

Brasil. Ministério da Justiça. (2015). Dar à luz na sombra: Condições atuais e possibilidades futuras para o exercício da maternidade por mulheres em situação de prisão. Brasília, DF: Ministério da Justiça, IPEA. Recuperado de https://www.justica.gov.br/news/201 clugar-de-crianca-nao-e-na-prisao-nem-longe-desua-mae201d-diz-pesquisa/pesquisa-dar-a-luz-na-sombra-1.pdf

Brasil. Ministério da Justiça e Segurança Pública. (2018). Levantamento Nacional de Informações Penitenciárias - INFOPEN Mulheres (2a ed.). Brasília, DF: Ministério da Justiça e Segurança Pública. Recuperado de http://depen.gov.br/DEPEN/depen/sisdepen/infopenmulheres/infopenmulheres_arte_07-03-18.pdf

Chaves, A. M., \& Silva, P. L. (2013). Representações Sociais. In L. Camino, A. R. R. Torres, M. E. O Lima, \& M. E. Pereira (Orgs.), Psicologia Social: Temas e teorias (2a ed., pp. 413-464). Brasília, DF: Technopolitik.

Coutinho, M. P. L., \& Do Bú, E. A. (2017). A técnica de associação livre de palavras sobre o prisma do software tri-deux-mots (version 5.2). Revista Campo do Saber, 3(1). Recuperado de http://periodicos.iesp.edu.br/index.php/campodosaber/article/view/72

Cortina, M. O. C. (2015). Mulheres e tráfico de drogas: Aprisionamento e criminologia feminista. Revista Estudos Feministas, 23(3), 761-778. doi:10.1590/0104026X2015v23n3p761

Cúnico, S. D., Brasil, M. V., \& Barcinski, M. (2015). A maternidade no contexto do cárcere: Uma revisão sistemática. Estudos e Pesquisas em Psicologia, 15(2), 509-528. Recuperado de http://pepsic.bvsalud.org/scielo.php?script=sci_arttext\&pid=S1808$42812015000200005 \& \operatorname{lng}=\mathrm{pt} \& \operatorname{lng}=\mathrm{pt}$

Diuana, V., Corrêa, M. C. D. V., \& Ventura, M. (2017). Mulheres nas prisões brasileiras: Tensões entre a ordem disciplinar punitiva e as prescrições da maternidade. Physis: Revista de Saúde Coletiva, 27(3), 727-747. doi:10.1590/s0103-73312017000300018

Ferrari, I. F., \& Fam, B. M. (2016). Mulheres e filhos encarcerados: Uma realidade institucional. Estudos \& Pesquisas em Psicologia, 16(4), 1153-1169. Recuperado de https://www.e-publicacoes.uerj.br/index.php/revispsi/article/view/33442/24157

Franco, M. L. P. B. (2004). Representações sociais, ideologia e desenvolvimento da consciência. Cadernos de Pesquisa, 34(121), 162-188. Recuperado de http://publicacoes.fcc.org.br/ojs/index.php/cp/article/view/493/497 
França, M. H. O. (2014). Criminalidade e prisão feminina: Uma análise da questão de gênero. Revista Ártemis, 18(1), 212-227. Recuperado de https://periodicos.ufpb.br/ojs2/index.php/artemis/article/view/22547

Germano, I. M. P., Monteiro, R. Á. F. G., \& Liberato, M. T. C. (2018). Criminologia crítica, feminismo e interseccionalidade na abordagem do aumento do encarceramento feminino. Psicologia: Ciência e Profissão, 38(spe2), 27-43. doi:10.1590/19823703000212310

Jesus, A. C. F., Oliveira, L. V. O., Oliveira, E. A., Brandão, G. C. G., \& Costa, G. M. C. (2015). O significado e a vivência do abandono familiar para presidiárias. Revista Ciência e Saude, 8(1), 19-25. doi:10.15448/1983-652X.2015.1.19535

Leal, M. C., Ayres, B. V. S., Esteves-Pereira, A. P., Sánchez, A. R., \& Larouzé, B. (2016). Nascer na prisão: Gestação e parto atrás das grades no Brasil. Ciência \& Saúde Coletiva, 21(7), 2061-2070. doi:10.1590/1413-81232015217.02592016

Lermen, H. S., Gil, B. L., Cúnico, S. D., \& Jesus, L. O. (2015). Saúde no cárcere: Análise das políticas sociais de saúde voltadas à população prisional brasileira. Physis: Revista de Saúde Coletiva, 25(3), 905-924. doi:10.1590/S0103-73312015000300012

Lima, G. M. B. (2013). A vida de mulheres na prisão: Legislação, saúde mental e superlotação em João Pessoa - PB (Tese de Doutorado). Fiocruz, Escola Nacional de Saúde Pública Sérgio Arouca, João Pessoa, PB, Brasil. Recuperado de https://www.arca.fiocruz.br/bitstream/icict/26389/1/492.pdf

Lima, G. M. B., Pereira Neto, A. F., Amarante, P. D. C., Dias, M. D., \& Ferreira Filha, M. O. (2013). Mulheres no cárcere: Significados e práticas cotidianas de enfrentamento com ênfase na resiliência. Saúde em Debate, 37(98), 446-456. doi:10.1590/S010311042013000300008

Minayo, M. C. S. (2012). Análise qualitativa: Teoria, passos e fidedignidade. Ciência \& Saúde Coletiva, 17(3), 621-626. doi:10.1590/S1413-81232012000300007

Moscovici, S. (2012). A Psicanálise, sua Imagem e seu Público. Petrópolis: Vozes.

Nogueira-Martins, M. C. F., \& Bógus, C. M. (2004). Considerações sobre a metodologia qualitativa como recurso para o estudo das ações de humanização em saúde. Saúde $e$ Sociedade, 13(3), 44-57. doi:10.1590/S0104-12902004000300006

Novaes, E. D., \& Murari, A. P. (2010). Uma Reflexão Teórico-sociológica acerca da inserção da Mulher na Criminalidade. Revista Sociologia Jurídica, (10). Recuperado de https://sociologiajuridicadotnet.wordpress.com/uma-reflexao-teorico-sociologicaacerca-da-insercao-da-mulher-na-criminalidade/ 
Ormeño, G, \& Stelko-Pereira, A. C. (2015). Filhos nascidos no cárcere e as dificuldades do exercício da maternidade em ambiente prisional. Psicologia Argumento, 33(82), 432445. doi:10.7213/psicol.argum.33.082.AO07

Pádua, T. A., \& Barros, V. A. (2018). Considerações sobre o trabalho nas prisões e os equívocos da ressocialização. Revista Trabalho (En)Cena, 3(3), 58-75. doi:10.20873/2526-1487V3N3P58

Reinert, M. (1993). “Quelques problèmes méthodologiques posés par l'analyse de tableaux 'Énonces x Vocabulaire". Paper presented at Journées internationales d'analyse statistique des données textuelles, Montpellier, France. Recuperado de http://www.image-zafar.com/sites/default/files/publications/jadt1993montpellier.pdf

Saraiva, E. R. A., Coutinho, M. P. L., \& Miranda, R. S. (2011). O emprego do Software Alceste e o desenvolvimento do mundo lexical em pesquisa documental. In M. P. L. Coutinho, \& E. R. A. Saraiva (Orgs.), Métodos de pesquisa em psicologia social: Perspectivas qualitativas e quantitativas (pp. 67-94). João Pessoa, PB: Editora Universitária.

Simões, V. F. N. (2013). Filhos do cárcere: Limites e possibilidades de garantir os direitos fundamentais dos filhos das mulheres privadas de liberdade no Brasil. Porto Alegre: Núria Fabris.

Supremo Tribunal Federal (2018) Habeas Corpus 143.641. Todas as mulheres submetidas à prisão cautelar no sistema penitenciário nacional, que ostentem a condição de gestantes, de puérperas ou de mães com crianças com até 12 anos de idade sob sua responsabilidade, e das próprias crianças. Relator: Ricardo Lewandowski. Recuperado de

http://www.stf.jus.br/arquivo/cms/noticiaNoticiaStf/anexo/HC143641final3pdfVoto.p df

\section{Endereço para correspondência}

\section{Adriele Vieira de Lima Pinto}

Rua Alberto de Brito, 845, Jaguaribe, João Pessoa - PB, Brasil. CEP 58015-320

Endereço eletrônico: adrielevieira_8@ hotmail.com

\section{Maria da Penha de Lima Coutinho}

Avenida Manoel Cavalcanti de Sousa, 120, ed. V Pirâmide, apto 1101, Cabo Branco, João Pessoa - PB, Brasil. CEP 58045-090

Endereço eletrônico: mplcoutinho@gmail.com 


\section{Jaqueline Gomes Cavalcanti}

Avenida Aragão e Melo, 861, Torre, João Pessoa - PB, Brasil. CEP 58040-102

Endereço eletrônico: gomes.jaqueline@gmail.com

\section{Karla Costa Silva}

Rua Nozinho Brandão, 227, Castelo Branco, João Pessoa - PB, Brasil. CEP 58050-450

Endereço eletrônico: karlacs18@gmail.com

Recebido em: 21/10/2019

Reformulado em: 28/04/2020

Aceito em: 01/05/2020

\section{Notas}

* Psicóloga, graduada pela Universidade Federal da Paraíba, Mestre em Psicologia Social pela mesma Instituição de Ensino.

** Coordenadora do Curso de Psicologia do Instituto de Educação Superior da Paraíba, professora da PósGraduação em Psicologia Social da Universidade Federal da Paraíba.

*** Psicóloga, Professora do Instituto de Educação Superior da Paraíba, Doutora em Psicologia Social pela Universidade Federal da Paraíba.

**** Psicóloga, servidora do Instituto Federal de Educação de Pernambuco, Mestre em Psicologia Social pela Universidade Federal da Paraíba.

Agradecimentos: Agradecemos à Gerência Executiva de Ressocialização do Estado da Paraíba por ter consentido a realização do nosso estudo e de maneira especial, a todas as mães privadas de liberdade que aceitaram participar desta pesquisa.

Financiamento: A pesquisa relatada no manuscrito foi financiada pela bolsa de doutorado da primeira autora (CAPES, No. Processo 88882.440895/2019-01).

Este artigo de revista Estudos e Pesquisas em Psicologia é licenciado sob uma Licença Creative Commons Atribuição-Não Comercial 3.0 Não Adaptada. 